\section{IJ§ER}

ISSN: 2149-5939
International Journal of Social Sciences and Education Research

Online, http://dergipark.gov.tr/ijsser

Volume: 1(2), 2015

\title{
Mesleki eğitim finansmanı
}

Financing vocational education

\begin{abstract}
Mehmet Durnalı1
Received Date: $01 / 02$ / 2015

Accepted Date: 01 / 04 / 2015

$\ddot{O} z$

Bu çalışmanın amacı Türkiye'nin mesleki eğitim sisteminin finansmanı hakkında bir çerçeve oluşturmaktır. Bu çalı̧̧ma için alanyazın araşstırması yapılmıştır. Ayrıca, Türkiye Cumhuriyeti Milli Ĕğitim Bakanlı̆̆ı, Mesleki ve Teknik Ĕ̈itim Genel Müdürlügü'ndeki ilgili uzmanlarla da birebir görüşerek ilgili yönetmelik, genelge ve kanunlar

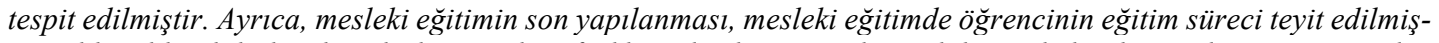
tir. Elde edilen bilgiler detaylı, bütüncül ve farklı açılardan sentezlenerek bu makale oluşturulmuştur. Bu çalışmada; öncelikle mesleki ve teknik ortä̈gretimin tanımına genel olarak yer verilmiştir. Mesleki eğitim sisteminin son yapılanmasından sonraki genel durum, mesleki ve teknik eğitim okul türleri aktarılmıştır. 2005/'06, 2009/'10, 2010/'11, 2011/'12, 2012/'13, 2013/'14, 2014/'15 eğitim ve ögretim yillarında mesleki ve teknik eğitim temel bileşenlerine klsaca yer verilmiştir. Daha sonra, mesleki ve teknik eğitim finansman kaynakları; özellikle ortaöğretim finansal kaynakları içerisindeki mesleki eğitim finansman kaynakları ve mesleki eğitimi geliştirme ve yaygınlaştırma fonu açıklanmıştır. Son bölümde ise, mesleki ve teknik eğitim finansman ve kaynak kullanımı-teşvik önerisinden bahsedilmiştir.
\end{abstract}

Anahtar sözcükler: Mesleki eğitim sistemi; Mesleki ve teknik eğitim okul türleri; Mesleki ve teknik eğitim finansmant; Mesleki eğitim finansmanı.

\begin{abstract}
The aim of this study is to establish a framework for financing of Turkey's vocational education system. The literature review is conducted for this study. In addition, one to one consultation with relevant experts from General Directorate of Vocational and Technical Education (of Ministry of National Education, Republic of Turkey) is executed and related regulations, circulars and laws is identified. Moreover, the recent restructuring of vocational training and the student's educational process in vocational education is confirmed. The information obtained synthesized from different angles, in details and integrated in order to create this article. In this article; first of all, general definition of vocational and technical education system, general state of vocational education system structured lastly and school types of vocational and technical education is explained, basic components in vocational and technical education of Turkey, 2005/'06, 2009/'10, 2010/'11, 2011/'12, 2012/'13, 2013/'14 and 2014/'15 education years, are analyzed and discussed shortly. Thereafter vocational and technical education financing sources; mainly vocational training financing sources mentioned in the secondary education financial resources and the official development and dissemination of vocational education fund are described in details. In the last part, the vocational and technical education financing and resource utilization-promoting proposals are presented.
\end{abstract}

Keywords: Vocational training system, School types of vocational and technical education, Vocational and technical education finance, Financing vocational education

\footnotetext{
${ }^{1}$ Hacettepe University, ANKARA/TURKEY, durnali@gmail.com
} 
Durnal1, M. (2015). Financing vocational education. International Journal of Social Sciences and Education Research, 1 (2), 572-583.

\section{Mesleki Eğitim Finansmanı}

Mesleki ve teknik ortaöğretim; ilköğretime dayalı en az dört yıllık zorunlu eğitimle öğrencilere genel kültür kazandırmanın yanı sıra, ilgi, istek ve yetenekleri doğrultusunda yükseköğretime hem yükseköğretime hem mesleğe veya geleceğe ve iş alanlarına hazırlayan eğitim öğretim sürecidir (MEB, 2013b, s. XV).

Selçuklular döneminde Ahilik adı altında kurulmuş bulunan esnaf ve sanatkâr teşkilatı; Osmanlılar döneminde de Lonca ve Gedik adları altında faaliyetlerini sürdürmüştür. 1839 yılında Tanzimat'ın ilanıyla mesleki eğitim adım adım bugün bilinen okul temelli bir yapıya doğru dönüşmüştür. Cumhuriyet dönemiyle birlikte esnaf ve ticaret odalarının da etkin olduğu, değişik türde örgün ve yaygın meslek okulları yoluyla mesleki eğitim devam etmiştir.

Mesleki eğitim 2011 yılına kadar;

- $\quad$ Erkek Teknik Öğretim Genel Müdürlüğü,

- $\quad$ Kız Teknik Öğretim Genel Müdürlüğü,

- $\quad$ Ticaret ve Turizm Öğretimi Genel Müdürlüğü,

- $\quad$ Sağlık İşleri Dairesi Başkanlığı ve

- Ç̧ıraklık, Mesleki ve Teknik Eğitimi Geliştirme ve Yaygınlaştırma Dairesi Başkanlığ tarafından gerçekleştirilmiş, 652 sayılı Millî Eğitim Bakanlığının Teşkilat ve Görevleri Hakkında Kanun Hükmünde Kararname ile Mesleki ve Teknik Eğitim Genel Müdürlüğü kurularak bu tarihten itibaren tek çatı altına toplanmıştır (MEB, 2015a).

Şekil 1. Mesleki ve Teknik Eğitim Okul Türleri (MEB, 2012a).

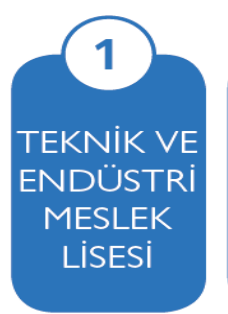

- Anadolu Teknik Lise

- Anadolu Meslek Lisesi

- Endüstri Meslek Lisesi

- Teknik Lise

- Denizcilik Meslek Lisesi

- Denizcilik Anadolu Meslek Lisesi

- Tarım Meslek Lisesi

- Tarım Anadolu Meslek Lisesi

- Tapu Kadas tro Meslek Lisesi
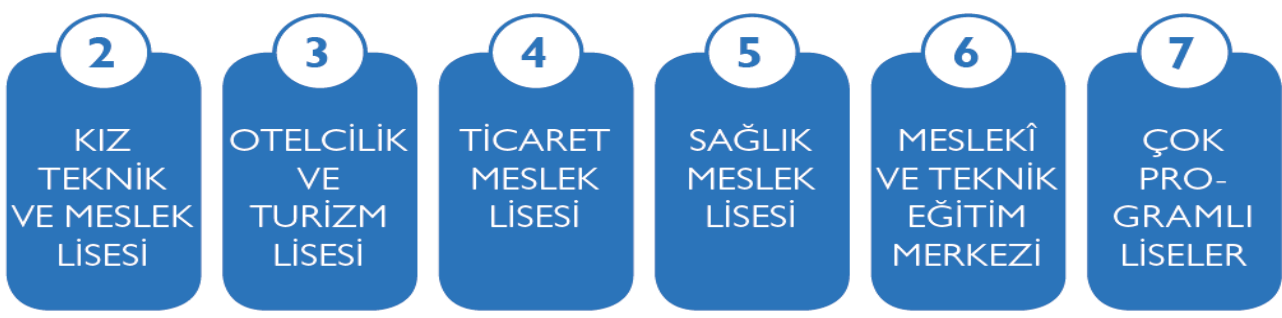

- Anadolu Kız Teknik Lisesi

- Anadolu Kız Meslek Lisesi

- Kız Teknik Lisesi

- Kız Meslek Lisesi

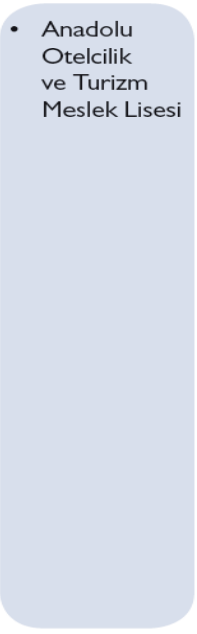

- Ticaret Meslek Lisesi

- Anadolu Ticaret Meslek Lisesi

- Adalet Meslek Lisesi

- Anadolu İletişim Meslek Lisesi

\section{- Anadolu}

Sağlık Meslek Lisesi

- Sağlık Meslek Lisesi$$
\text { . }
$$
- Lise Teknik Eğitim - Meslek Lisesi Merkezi

- İmam-Hatip Lisesi programları uygulanmaktadır

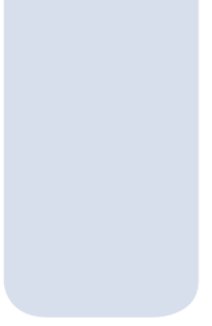

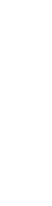


Durnalı, M. (2015). Mesleki eğitim finansmanı. International Journal of Social Sciences and Education Research, 1 (2), 572-583.

01.05.2014 tarih ve 176074 sayılı genelge (MEB, 2014a)'den önce mesleki ve teknik eğitimde okul türleri yukarıda Şekil 1'de gösterildiği gibi Mesleki ve Teknik Ortaöğretimde Okul Çeşitliliğinin Azaltılması konulu bu genelge ile mesleki ve teknik eğitimde okul yapılanması şu şekilde oluşturulmuştur.

Şekil 2. Güncel Mesleki ve Teknik Eğitim Okul türleri (MEB, 2014a).

\begin{tabular}{|c|c|c|c|}
\hline $\begin{array}{l}\text { MESLEKİ VE TEK- } \\
\text { NİK ANADOLU Lİ- } \\
\text { SESİ }\end{array}$ & $\begin{array}{l}\text { ÇOK PROGRAMLI } \\
\text { ANADOLU LİSESI }\end{array}$ & $\begin{array}{l}\text { MESLEKİ VE TEKNİK } \\
\text { EĞİTIM MERKEZİ } \\
\text { (METEM) }\end{array}$ & $\begin{array}{c}\text { İKİLİ MESLEKİ } \\
\text { EĞİTİM }\end{array}$ \\
\hline $\begin{array}{l}\text { Anadolu meslek prog- } \\
\text { ramı } \\
\text { Anadolu teknik prog- } \\
\text { ramı }\end{array}$ & $\begin{array}{l}\text { Anadolu meslek prog- } \\
\text { ramı } \\
\text { Anadolu teknik programı } \\
\text { Anadolu Lisesi programı } \\
\text { Anadolu imam hatip li- } \\
\text { sesi programı }\end{array}$ & $\begin{array}{l}\text { Anadolu meslek prog- } \\
\text { ramı } \\
\text { Anadolu teknik prog- } \\
\text { ramı } \\
\text { Belge ve sertifika prog- } \\
\text { ramları }\end{array}$ & Belge ve sertifika \\
\hline
\end{tabular}

Şekil 3. Öğrencinin yönelme ve Mesleki Eğitim süreci (MEB, 2012a).

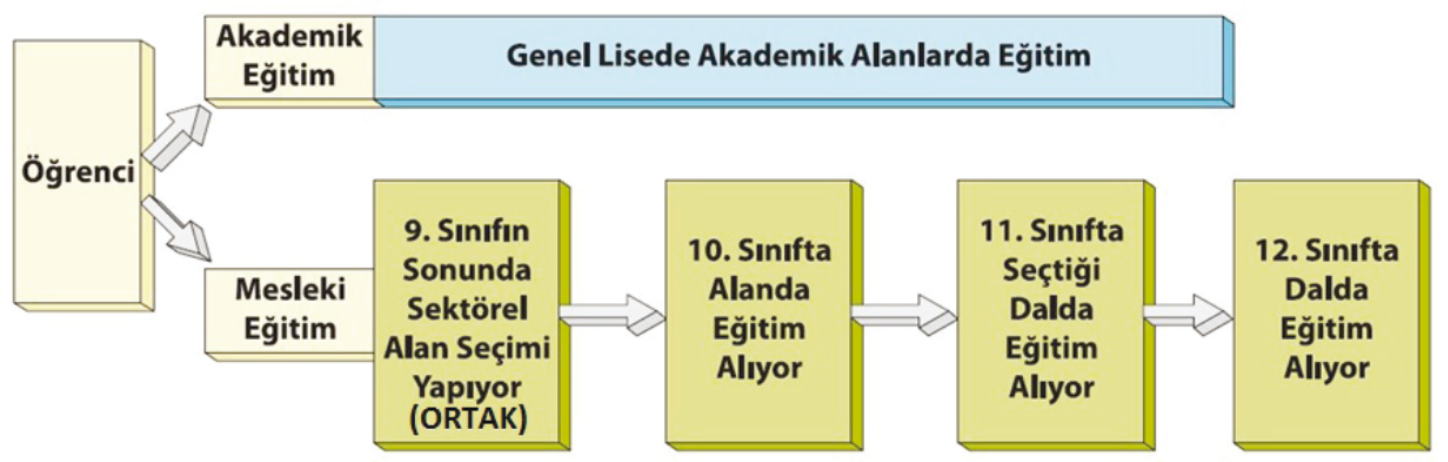

Resmi Gazete (2002)'de yayınlanan Mesleki ve Teknik Eğitim Yönetmeliği temelinde öğrencinin yönelme ve mesleki eğitim süreci ile ilgili şu açıllamayı yapmak olanaklıdır. Mesleki eğitimi seçen bir öğrenci, 9. sınıf sonunda bir alan seçmektedir (Örneğin bilişim teknolojileri alanı). 10. sınıfta bu alanda eğitim gördükten sonra 10. sınıfın sonunda bu alanın bir dalını seçmektedir. 11. ve 12. sınıfta bu dalda eğitim görmektedir. Ayrıca 12. sınıfta staj görmektedir. Örneğin; 10. sınıfta biliş̧im teknolojileri alanında eğitim almış bir öğrenci, 11. sınıfta bu alanın şu dallarından; ağ işletmenliği, bilgisayar teknik servisi, veri tabanı programcilığı ve web programcıllı̆̆ birini seçerek eğitimine devam etmektedir. Ayrıca, Anadolu liseleri ile Mesleki ve Teknik Eğitim liselerinin 9. sınıflarında ortak, aynı dersler verilmektedir. Sadece Mesleki Eğitim Liselerinde Anadolu Lisesinden farklı olarak 2 saatlik Mesleki Gelişim dersi fazladan verilmektedir; okul türüne göre 9. sınıf sonunda veya 10. sınıf 1. dönem sonunda Anadolu lisesindeki bir öğrenci Mesleki eğitime, mesleki eğitimdeki bir öğrenci de Anadolu lisesine geçiş yapabilmektedir.

Bu k1sımda; 2005/'06, 2009/'10, 2010/'11, 2011/'12, 2012/'13, 2013/'14, 2014/'15 eğitim ve öğretim yıllarında mesleki ve teknik eğitim temel bileşenlerine genel bir bakış yapılacaktır. 
Durnal1, M. (2015). Financing vocational education. International Journal of Social Sciences and Education Research, 1 (2), 572-583.

Şekil 4. Mesleki ve Teknik Ortaöğretimde öğrenci sayıları

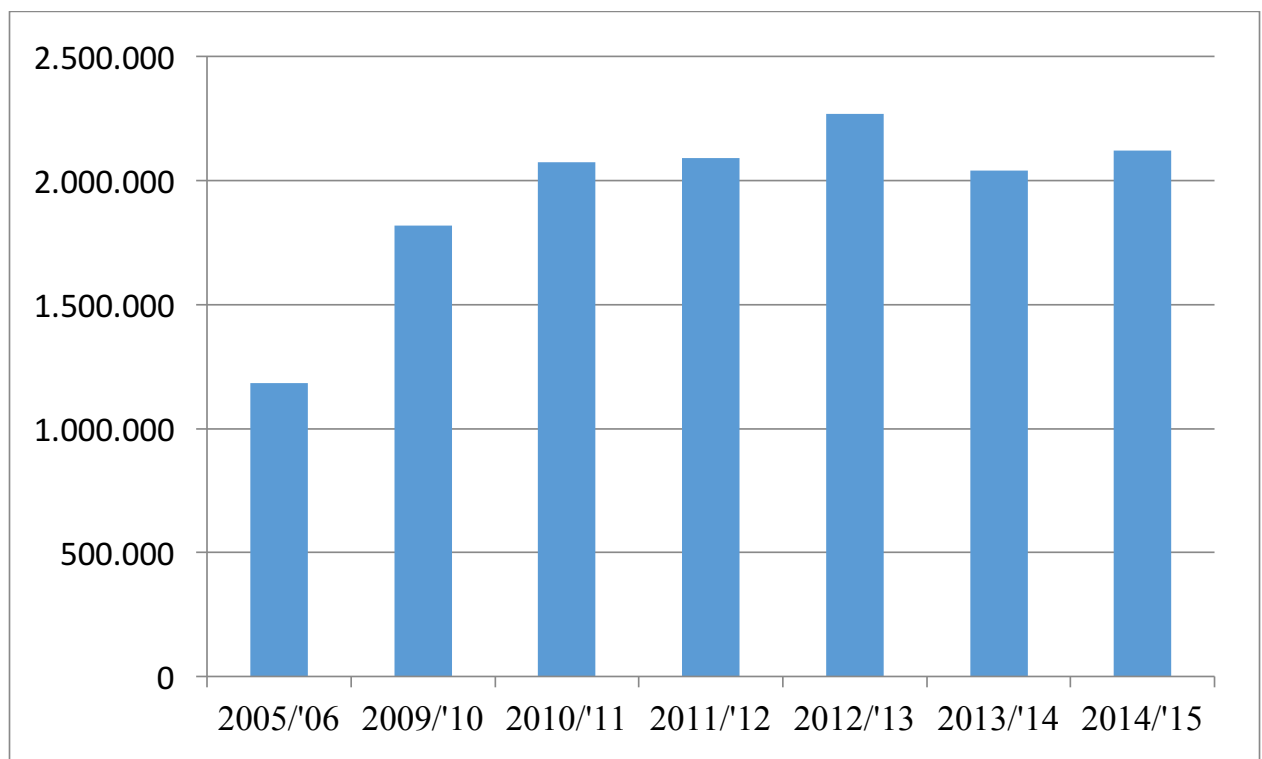

(MEB, 2006;2010;2011;2012b;2013b;2014b;2015b)

Şekil 4'teki grafik, mesleki ve teknik ortaöğretimde 2005/'06, 2009/'10, 2010/'11, 2011/'12, 2012/'13, 2013/'14, 2014/'15 eğitim ve öğretim yıllarında Türkiye genelinde öğrenci sayılarını göstermektedir. Bu grafik, mesleki ve teknik ortaöğretimde Türkiye genelinde 2005/'06 eğitim ve öğretim yılında öğrenci sayısının 1.182.637 olduğunu göstermektedir. Bu sayı 2009/'10, 2010/'11, 2011/'12, 2012/'13, 2013/'14, 2014/'15 eğitim ve öğretim yıllarında yaklaşık 1.000 .000 artış göstermiştir. 2012/'13 eğitim ve öğretim yılı, 2.269.651 Türkiye geneli öğrenci sayısı ile son altı eğitim ve öğretim yılının en yükseği ve ayrıca Türkiye Cumhuriyeti tarihinin en yüksek öğrenci sayısı olabileceği tespit edilmiştir.

Şekil 5. Mesleki ve Teknik Ortaöğretimde öğretmen sayıları

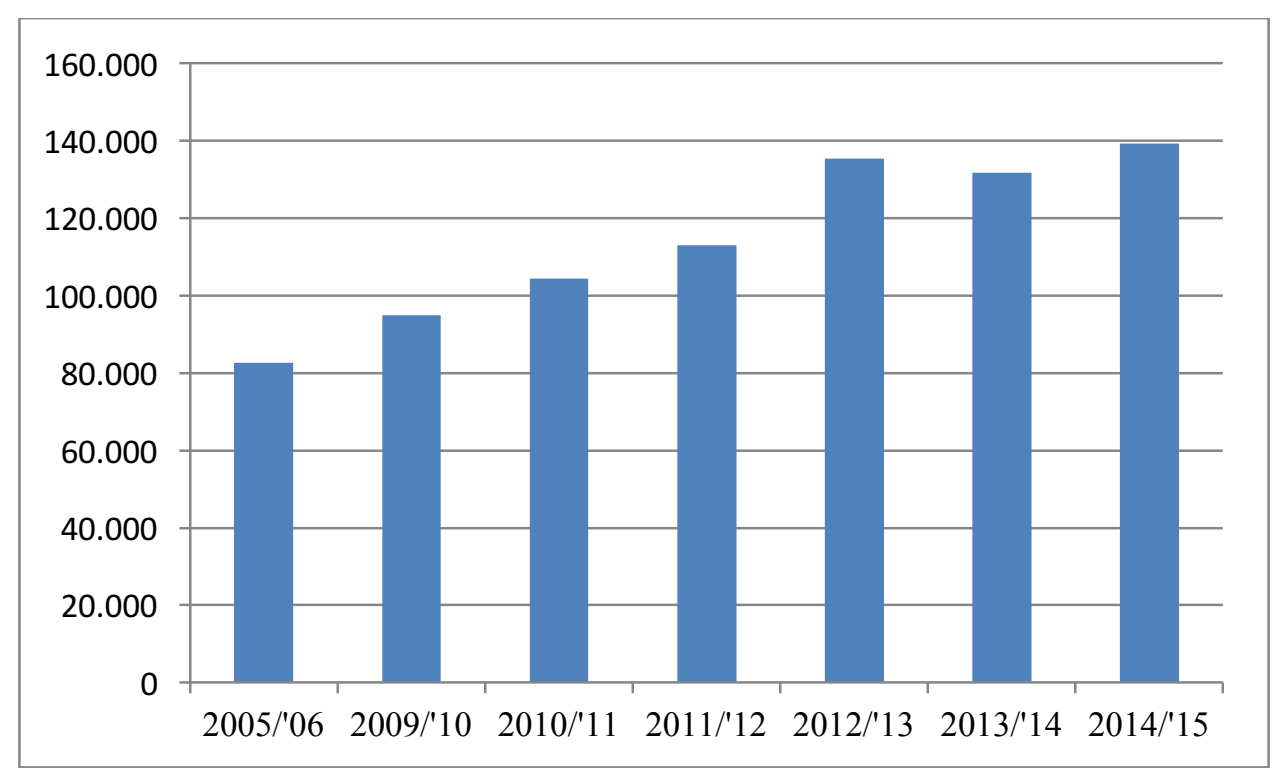

(MEB, 2006;2010;2011;2012b;2013b;2014b;2015b) 
Durnalı, M. (2015). Mesleki eğitim finansmanı. International Journal of Social Sciences and Education Research, 1 (2), 572-583.

Şekil 5'teki grafikte, mesleki ve teknik ortaöğretiminde 2005/'06, 2009/'10, 2010/'11, 2011/'12, 2012/'13, 2013/'14, 2014/'15 eğitim ve öğretim yıllarına ait Türkiye genelinde öğretmen sayıları kıyaslanmaktadır. Bu grafik, mesleki ve teknik ortaöğretimde Türkiye genelinde 2005/'06 eğitim ve öğretim yılında öğretmen sayısının 82.736 olduğunu göstermektedir. Bu sayı 2009/'10, 2010/'11, 2011/'12, 2012/'13, 2013/'14, 2014/'15 eğitim ve öğretim yıllarında sırayla 94.966, 104.327, 113.098, 135.502, 131.732, 139.374'tür. 2014/'15 eğitim ve öğretim y1lı, 139.374 Türkiye geneli öğretmen sayısı ile son altı eğitim ve öğretim yılının en yükseği ve ayrıca mesleki ve teknik ortaöğretimde Türkiye Cumhuriyeti tarihinin en yüksek öğretmen sayısı olabileceği tespit edilmiştir.

Şekil 6. 2014/'15 eğitim ve öğretim yıl1, Meslekî ve teknik ortaöğretim öğrenci sayısı toplamının Genel ortaöğretim toplamına oranı (MEB, 2015b)

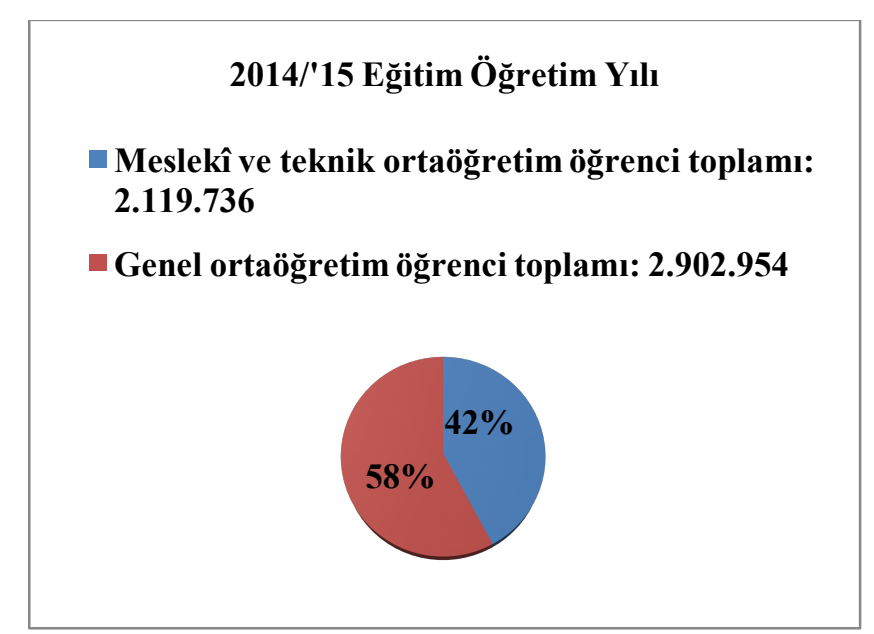

Şekil 7'ye göre, 2014/'15 eğitim ve öğretim yılında meslekî ve teknik ortaöğretimin ortaöğretimdeki payı \% 42'dir. Genel ortaöğretimin ortaöğretimdeki payı ise \%58'dir. Genel ortaöğretim; Ortaöğretim Genel Müdürlüğü ve Özel Öğretim Kurumları Genel Müdürlüğüne bağlı ortaöğretim okullarına, diğer bakanlık ve kurumlara bağlı meslek lisesi (Polis Koleji), mesleki tekniğe ve Din Öğretimine devredilen liseler ve Açıköğretim Lisesine kayıtlı öğrencileri içermektedir. Meslekî ve teknik ortaöğretim ise Mesleki ve Teknik Eğitim Genel Müdürlüğ̈̈, Özel Eğitim ve Rehberlik Hizmetleri Genel Müdürlüğüne bağlı ortaöğretim okullarına, diğer bakanlık ve kurumlara bağl1 meslek lisesi (konservatuar), Özel Öğretim Kurumları Genel Müdürlüğü (Özel) ve Açıköğretim Lisesine kayıtlı öğrenci sayılarını kapsamaktadır.

Şekil 7. Mesleki ve Teknik Lise Resmi / Özel (MEB, 2015b)

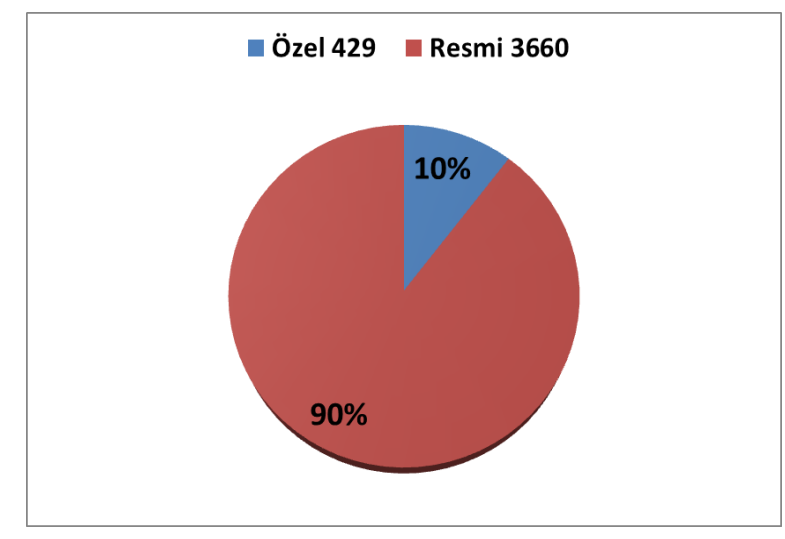


Durnal1, M. (2015). Financing vocational education. International Journal of Social Sciences and Education Research, 1 (2), 572-583.

Şekil 7'deki grafik şunu göstermektedir. 2014/'15 eğitim ve öğretim y1lı Milli Eğitim İstatistik (MEB, 2015b) verilerine göre Türkiye genelinde Özel Öğretim Genel Müdürlüğüne bağl1, 429 Mesleki ve Teknik lisede 75.890 öğrenci öğrenim görmüş iken, 3.660 resmi okulda, Açıköğretim lisesi hariç, 1.832 .460 öğrenci eğitim görmüştür. Şekil 7'deki grafikten de anlaşılacağı üzere Türkiye'de mesleki eğitimde finansmanın büyük kısmı devlet tarafından sağlamaktadır.

Şekil 8. OECD ülkelerinde mesleki ve teknik öğretim öğrenci başına yıllık birim harcamalarına ilişkin bir kesit (2011 yılı, ABD doları) (OECD, 2014).

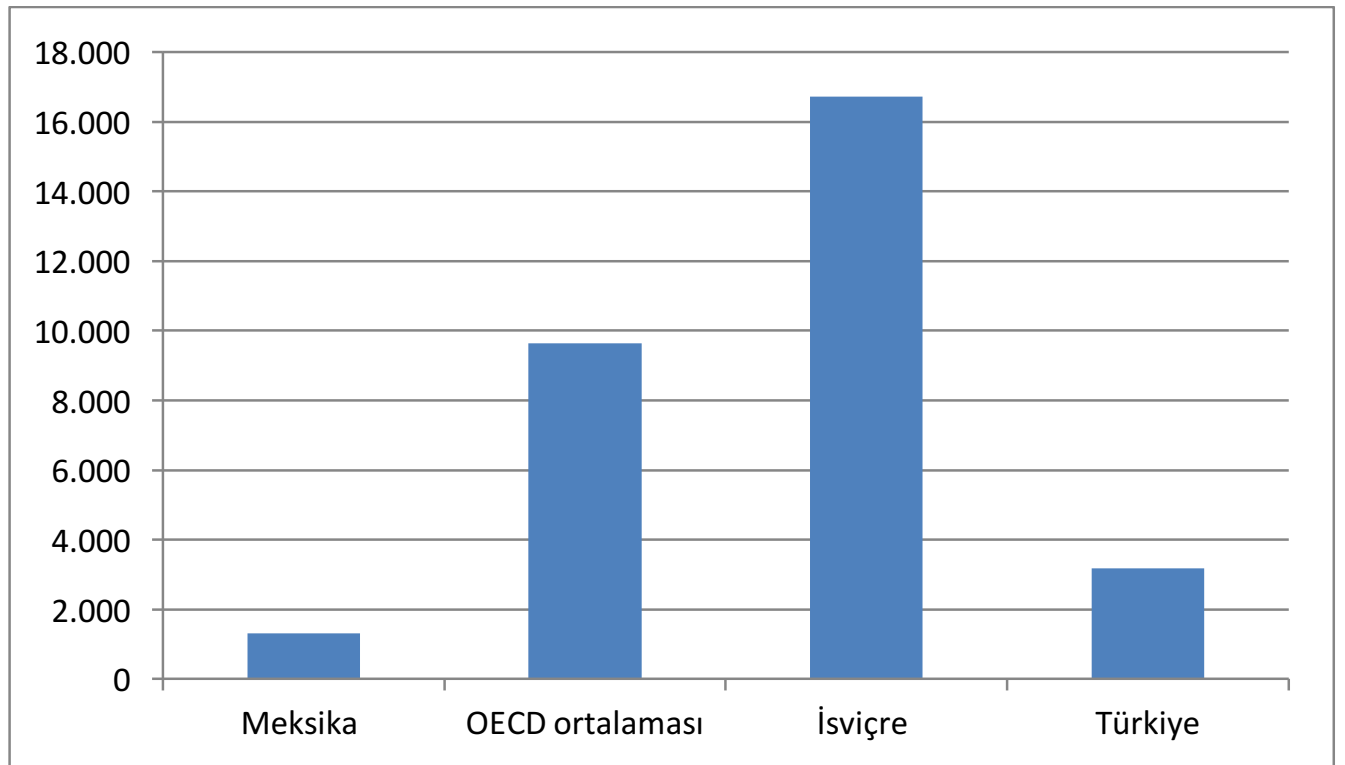

Şekil 8'de OECD ülkelerinde 2011 yılına ait mesleki ve teknik öğretim öğrenci başına yıllık birim harcamalarına ilişkin bir kesit aktarılmaktadır. 2011'deki bu verilere göre 1.302 ABD doları ile Meksika, mesleki ve teknik öğretimde öğrenci başına yıllık en az harcayan ülke iken İsviçre yıllık 16.730 ABD doları ile en çok harcama yapan ülkedir. Türkiye ise 3.181 ABD doları ile OECD ortalaması olan 9.643 ABD dolarının yaklaşık 1/3 oranında daha az bir harcama gerçekleştirmektedir.

222 sayılı İlköğretim ve Eğitim Kanunu ile 1739 sayılı Milli Eğitim Temel Kanunu, ortaöğretimin finansman kaynaklarına açık olarak yer vermemiştir (Gümüş ve Şişman, 2012, s. 86). 3308 Mesleki Eğitim Kanunu İle Mesleki Eğitimi Geliştirme ve Yaygınlaştırma Fonu oluşturulmuştur (Resmi Gazete,1986). Bu fondan elde edilen kaynaklar, özellikle mesleki ve ortaöğretim finansmanında kullanılmasına rağmen oldukça düşük düzeydedir. Ortaöğretim (mesleki eğitim) kurumlarının okul binası, tesisler gibi büyük yatırım gerektiren ihtiyaçları Milli Eğitim Bakanlığı bütçesiyle karşılanmaktadır. Bu okullarda görevli idareci, öğretmenler ve öğreticilerin maaşları da Milli Eğitim Bakanlığı bütçesinden karşılanmaktadır (Gümüş ve Şişman, 2012, s. 86).

5.6.1986 tarih ve 3308 sayılı Çıraklık ve Meslek Eğitimi Kanununun 32. Maddesinde belirtilen Mesleki eğitimi geliştirme ve yaygınlaştırma fonunun kaynaklarını;

a) Her yıl Bakanlık bütçesine bu maksatla konulacak ödenek, 
Durnalı, M. (2015). Mesleki eğitim finansmanı. International Journal of Social Sciences and Education Research, 1 (2), 572-583.

b) 27/11/1984 tarihli ve 84/8800 sayılı Kararnamenin Eki Kararla kurulan "Geliştirme ve Destekleme Fonu'ndan Bakanlar Kurulunca bu fon gelirinin \% 10'undan az olmamak üzere belirlenecek miktarda yapılacak aktarmalar,

c) Bakanlık bünyesinde bulunan döner sermaye işletmelerinin karları,

d) Bakanlığa bağlı kurumlarda eğitim öğretimde üretilen malların satışından elde edilen hasılatlar,

e) (Değişik: 25/6/1992 - 3824/25 md.) Gelir ve kurumlar vergisi mükellefleri (Orman Genel Müdürlügü hariç) (3) ile sorumluları tarafından hesaplanan gelir ve kurumlar vergileri üzerinden ayrıca ödenen fon payı hasılatından, Bakanlar Kurulu Kararı ile belirlenen oranda ayrılacak pay,

f) 5590 sayılı Ticaret ve Sanayi Odaları, Deniz Ticaret Odalar1, Ticaret Borsaları ve Türkiye Ticaret, Sanayi, Deniz Ticaret Odaları ve Ticaret Borsaları Birliği Kanununa 2567 sayılı Kanunla eklenen ek 3 üncü madde gereğince odalar, borsalar ve birlikler tarafından eğitim gayesiyle bütçelerinden ayrılan payların \% 50'si (4),

g) 507 sayılı Esnaf ve Küçük Sanatkârlar Kanununa 3153 sayılı Kanunla eklenen ek 6 ncı madde gereğince, esnaf ve küçük sanatkâr dernekleri, birlikleri federasyonları ve konfederasyonları tarafından eğitim gayesiyle gayri safi gelirlerinden ayrılan payların \% 50'si,

h) 2821 sayılı Sendikalar Kanununun 44 üncü maddesine göre işçi sendika ve konfederasyonlarınca gelirlerinden eğitim maksadıyla ayrılan payların $\% 25^{\prime}$ i,

i) 2821 sayılı Kanuna göre faaliyette bulunan işveren sendika ve konfederasyonlarının bir önceki yıl aidat gelirlerinin \% 5'i nispetinde ayıracakları paylar,

j) 492 sayılı Harçlar Kanununun 108 inci maddesi ile aynı Kanuna bağlı (8) sayılı tarifenin VII numaralı pozisyonunda yazılı diploma harçları. Bu harçlar makbuz karşıllı̆ıında ödenir. Bunun şeklini ve Fona ödenmesiyle ilgili usul ve esasları düzenlemeye Maliye ve Gümrük Bakanlığı yetkilidir.

(Değişik paragraf: 25/6/1992 - 3824/25 md.) Yukarıda f, g, h, i ve j bentlerinde sorumlu tutulanlar tarafından hesaplanarak ödenmesi gereken fona ait meblağ hakkında 6183 sayılı Amme Alacaklarının Tahsil Usulü Hakkında Kanun hükümleri uygulanır.

k) Fonun mal varlığından elde edilen gelirler,

1) Bağış, yardım ve diğer gelirler teşkil eder (Resmi Gazete, 1986).

Ancak, yukarıda belirtilen 5.6.1986 tarihli ve 3308 sayılı Çıraklık ve Meslek Eğitimi Kanununun 32. Maddesi (Mesleki eğitimi geliştirme ve yaygınlaştırma fonunun kaynakları) aşağıdaki şekilde değiştirilmiştir.

a) Çıraklık, mesleki ve teknik eğitimi geliştirme ve yaygınlaştırma hizmet ve faaliyetlerinde kullanılmak üzere;

1) Bakanlık bünyesinde bulunan döner sermaye işletmelerinin kârları,

2) Bakanlığa bağlı kurumlarda eğitim öğretimde üretilen malların satışından elde edilen gelirler,

3) Bağış, yardım ve diğer her türlü gelirler, 
Durnal1, M. (2015). Financing vocational education. International Journal of Social Sciences and Education

Research, 1 (2), 572-583.

Milli Eğitim Bakanlığı Merkez Saymanlık Müdürlüğü hesabına yatırılır. Yatırılan bu tutarlar Maliye Bakanlığınca bir yandan genel bütçeye özel gelir, diğer yandan Bakanlık bütçesinde açılacak tertiplere özel ödenek kaydedilir. Bu suretle ödenek kaydedilen miktarlardan yılı içerisinde harcanmayan tutarları ertesi yıl bütçesine devren özel gelir ve ödenek kaydetmeye Maliye Bakanı yetkilidir.

b) Çıraklık, mesleki ve teknik eğitimi geliştirme ve yaygınlaştırma hizmet ve faaliyetlerinde kullanılmak üzere Bakanlık bütçesine özel ödenek kaydedilen bu tutarlar aşağıdaki hizmetlerin yerine getirilmesinde kullanılır:

1) Çıraklık, örgün ve yaygın mesleki ve teknik öğretim kurumlarında görevli yönetici, öğretmen, uzman, kadrolu ve kadrosuz usta öğreticilerin nitelik ve niceliklerinin yükseltilmesi için yurt içinde eğitilmelerinde,

2) Mesleki ve teknik eğitim metotlarının ve araçlarının araştırılması, geliştirilmesi ve yaygınlaştırılmasında,

3) Çıraklık, örgün ve yaygın mesleki ve teknik öğretim kurumlarının atölye ve laboratuvarları için makine, araç, takım ve teçhizat alınması, gerektiğinde kiralanması, bunların bakım ve tamirinde,

4) Çıraklık, örgün ve yaygın mesleki ve teknik eğitim kurumlarında görevli kadrolu ve kadrosuz atölye ve meslek dersi öğretim elemanlarına asli görevleri dışında, okulda ve işyerlerinde yapılan eğitimle ilgili normal maaş ve ücretlerine ilave ek ücret ödenmesinde,

5) Çıraklık, örgün ve yaygın mesleki teknik eğitimle ilgili her türlü yayınların hazırlatılması, tercümesi, çoğaltılması, satın alınması ve dağıtılmasında,

6) Çeşitli mesleklerde çalışmakta olanlara hizmet içinde ve mesleklerinde gelişmeleri için gerekli bilgi ve becerilerin kazandırılması için Bakanlığa bağlı eğitim kurumlarında kurslar, seminerler ve eğitim programları düzenlenmesinde,

7) İş öncesi eğitimi, yaygın ve çıraklık eğitiminde,

8) Çıraklık ve Mesleki Eğitim Kurulu ile İl Çıraklık ve Mesleki Eğitim Kurulu toplantılarına katılan başkan, üye, müşavir üye, imtihan ve mesleki ihtisas komisyonu üyelerine Maliye Bakanlığının uygun görüşü üzerine tespit edilecek miktarda verilecek yolluk ve huzur hakkı ödemelerinde (Resmi Gazete, 3 Temmuz 2001).

Gümüş ve Şişman (2012, s. 86-87)'a göre ortaöğretim finansal kaynakları şunlardır:

Konsolide bütçeden ayrılan kaynaklar.

İl özel idarelerinden ayrılan kaynaklar.

3308 sayılı yasa gereğince Mesleki Eğitimi Geliştirme ve Yaygınlaştırma Fonu.

4306 sayılı yasa gereğince Eğitime Katkı Payı.

Döner sermaye işletmelerinden sağlanan gelirler.

Yurt dışı ülke ve kuruluşlardan sağlanan dış krediler, burslar, bağışlar ve bilimsel araştırma kredileri.

Halkın kişi ve kuruluşlar olarak eğitime katkıları, bağışlar. 
Durnalı, M. (2015). Mesleki eğitim finansmanı. International Journal of Social Sciences and Education Research, 1 (2), 572-583.

Dernek gelirleri(Okul yaptırma, onarım ve öğrenci koruma dernekleri vb.)

Türkiye'de hayırsever vatandaşlar, yaptırdıkları okullar ve eğitime yaptıkları değişik yardımlar ile mesleki eğitime finansal destek vermektedirler. Ayrıca yurt dışı kaynaklı (Dünya Bankası, Avrupa Birliği Fonları (Avrupa Sosyal Fonu, Avrupa Eğitim Vakfı, Avrupa Birliği Akdeniz Fonu, Leonardo da Vinci (Ldv), IPA) fonların desteğiyle Mesleki Eğitim ve Öğretim Sistemini Güçlendirme Projesi (MEGEP), Meslekî ve Teknik Eğitim Kurumlarının Modernizasyonu Projesi (MTEM), İnsan Kaynaklarının Mesleki Eğitim Yoluyla Geliştirilmesi Projesi (İKMEP), Orta Öğretim Projesi (OÖP) gibi projelerle de mesleki eğitime finansal girdiler sağlanabildiği tespit edilmiştir. Ayrıca çeşitli kuruluşların; örneğin, Tekstil İşveren Kuruluşları, KOSGEB, Gıda Sanayicileri Derneği, İşçi Sendikası ve diğer benzer kuruluşların okullara makine, bina yapımı ve burs olarak katkı yaptıkları tespit edilmiştir. Ayrıca, mesleki eğitim gören öğrencilerin velilerince de yapılan çeşitli miktarlarda yardımlar, harcamalar olabilmektedir.

24 Şubat 2012 yılında Antalya'da Meslekî ve Teknik Eğitim Genel Müdürlüğü'nce yapılan çalıştayda tespit edilen finansman, kaynak kullanımı ve teşvik eksikliği şunlardır:

1. Mesleki ve Teknik Eğitimde yatırım ve donatım malzemelerinin yetersizliği, hızla eskimesi ve yenilenme ihtiyacının karşılanamaması.

2. Teşvik eksikliği.

Finansman ve kaynak kullanımı-teşvik konusunda önerilen çözüm önerileri şunlardır:

1. Mesleki ve Teknik Eğitim okulları, organize sanayi bölgelerinde ve oluşturulacak sanayi sitelerinde kurulmalı, okul ve sektörün temsil edildiği etkileşimli bir yönetim kurulu oluşturulmal1,

2. İllerde sosyal ortakların ve belediyelerin katkılarıyla oluşturulacak fonlarla MTE desteklenmeli,

3. Kalkınma ajanslarından Mesleki ve Teknik Eğitime proje desteği sağlanması için çağrılar yayınlanmalı,

4. Özel Mesleki ve Teknik Eğitim kurumlarının açılması için devletin teşvik mekanizmasını belirlemesi ve uygulamaya geçirmesi sağlanmalıdır.

$\mathrm{Bu}$ çalışmada; mesleki eğitim sisteminin yapılanmasındaki son durum, mesleki ve teknik eğitim okul türleri ve programları, 2005/'06, 2009/'10, 2010/'11, 2011/'12, 2012/'13, 2013/'14, 2014/'15 eğitim ve öğretim yıllarında mesleki ve teknik eğitim temel bileşenlerine yer verilmiştir. Daha sonra, mesleki ve teknik eğitim finansman kaynakları; özellikle ortaöğretim finansal kaynakları içerisindeki mesleki eğitim finansman kaynakları ve mesleki eğitimi geliştirme ve yaygınlaştırma fonu açıklanmıştır. Son olarak, mesleki ve teknik eğitim finansman ve kaynak kullanımı-teşvik önerisinden bahsedilmiş̧ir.

\section{Kaynakça}

Gümüş, E. ve Şişman, M. (2012). Eğitim Ekonomisi ve Planlaması. Ankara: PegemA Yayınc1lık.

MEB, (2006). Milli Ĕgitim İstatistikleri Örgün Ĕgitim 2005-2006.

MEB, (2010). Milli Eğitim İstatistikleri Örgün Eğitim 2009-2010.

MEB, (2011). Milli Eğitim İstatistikleri Örgün Ĕgitim 2010-2011. 
Durnal1, M. (2015). Financing vocational education. International Journal of Social Sciences and Education Research, 1 (2), 572-583.

MEB, (2012a), Mesleki Teknik Eğitim Çalıştayl, Erişim: 1 Temmuz 2015, http://mtegm.meb.gov.tr/tr/dokumanlar/calistay/index.html\#/40/

MEB, (2012b). Milli Eğitim İstatistikleri Örgün Eğitim 2011-2012.

MEB, (2013b). Milli Eğitim İstatistikleri Örgün Eğitim 2012-2013.

MEB, (2014a). Mesleki ve Teknik Ortaöğretimde Okul Çeşitliliğinin Azaltılması konulu, 01.05.2014 tarih ve 176074 sayılı genelge. Erişim: 9 Eylül 2015, http://mevzuat.meb.gov.tr/html/mestekokulces $0 /$ mestekokulces $1 . \mathrm{html}$

MEB, (2014b). Milli Eğitim İstatistikleri Örgün Eğitim 2013-2014.

MEB, (2015a). Mesleki ve Teknik Eğitim Genel Müdürlüğü-Tarihçemiz. Erişim: 10 Eylül 2015, http://mtegm.meb.gov.tr/www/tarihcemiz/icerik/20

MEB, (2015b). Milli Ĕgitim İstatistikleri Örgün Ĕgitim 2014-2015.

OECD, (2014). Education at a Glance 2014: OECD Indicators. OECD Publishing. http://dx.doi.org/10.1787/eag-2014-en

Resmi Gazete, (1986). Mesleki Eğitim Kanunu.

Resmi Gazete, (2001). 4684 Bazı Kanun ve Kanun Hükmünde Kararnamelerde Değişiklik Yapılmasına Dair Kanun.

Resmi Gazete, (2002). Mesleki ve Teknik Eğitim Yönetmeliği. 
Durnalı, M. (2015). Mesleki eğitim finansmanı. International Journal of Social Sciences and Education Research, 1 (2), 572-583.

\section{Extended abstract in English}

The aim of this study is to establish a framework for the financing of Turkey's vocational education system. The literature review is conducted for this study. In addition, one to one consultation with relevant experts from General Directorate of Vocational and Technical Education (of Ministry of National Education, Republic of Turkey) is executed and related regulations, circulars and laws are identified. Moreover, the recent restructuring of vocational training and the student's educational process in vocational education are confirmed. The information obtained synthesized from different angles, in details and integrated in order to create this article.

In this article; first of all, general definition of vocational and technical education system is explained as vocational and technical education is educational process that prepares students for both higher education and for a profession or for life and employment areas according to their interests, wishes and capabilities as well as providing student with general knowledge with at least four years of compulsory education after primary education (MEB, 2013b, p. XV). The final structure of the vocational training system as in No. 652 Decree Law on the Organization and Duties of Ministry of National Education is explained. With this decree, General Directorate of Technical Education for Boys, General Directorate of Technical Education for Girls, General Directorate of Commerce and Tourism Education, Health Affairs Department, and Apprenticeship, Vocational and Technical Education Development and Promotion Department are assembled under one roof under the General Directorate of Vocational and Technical Education (MEB, 2015a).

New types of vocational and technical education schools whose legally bases on the circular on the Reduction of Vocational and Technical Secondary Education School Diversity (Date 05.01.2014 and numbered 176074) is emphasized. School types which are in four mainly are as follows: Vocational and Technical High School; Anatolian vocational program, Anatolian technical program. Multi-Program High School; Anatolian vocational program, Anatolian technical program, Anatolian high school program, Anatolian religious high school program. Vocational and Technical Education Center (METEM); Anatolian vocational program, Anatolia technical program, Certificate programs. Dual Vocational Training; certificate.

On the basis of Regulation of Vocational and Technical Education published in Official Gazette (2002), how students studying in vocational training handles vocational orientation and training process is explained in detail. Following that, basic components in the vocational and technical education are given and discussed briefly for the school years 2005 / '06, 2009 / '10, 2010 / '11, 2011 /'12, 2012 / '13, 2013 / '14, 2014 / '15. The number of students and of teachers of vocational and technical education are compared considering these academic years. For the 2014 / '15 academic year, the ratio of the sum of the total general secondary education to the number of students in vocational and technical education is given. For the 2014 / ' 15 school year, the share of vocational and technical education in secondary education is $42 \%$. The share of general secondary education in secondary education is $58 \%$.

General secondary education includes registered students who enrolled in the schools affiliated with General Directorate of Secondary Education, General Directorate of Private Education, vocational high schools (Police College) under other ministries and institutions, professional technical and religious schools and Open Education High Schools. On the other hand, the vocational and technical education includes registered students who enrolled in the schools under General Directorate of Vocational and Technical Education, General Directorate of Special Education and 
Guidance Services General Directorate of the secondary education schools, vocational school (conservatory) affiliated with other ministries and institutions, General Directorate of Private Education (Special) and the Open High School.

In later part of the article, number of students who enrolled in public and private vocational and technical high school is compared for the 2014 / ' 15 school year. Later on, according to OECD data in 2011, a section on the annual spending units per student in vocational and technical education in OECD countries is emphasized. According to these data, while Mexico is the country with spending the least per student in vocational and technical education with $\$ 1,302$ annually in OECD countries, Switzerland is the country with the highest spending per student in vocational and technical education with $\$ 16.730$ annually. Turkey is spending less than $1 / 3$ of the OECD average which is 9643 US dollars, with 3,181 US dollars.

Thereafter in the another part of the paper, vocational and technical education financing sources; mainly vocational training financing sources mentioned in the secondary education financial resources and the official development and dissemination of vocational education fund are described in details. In the last part, the vocational and technical education financing and resource utilization-promoting proposals (obtained from a vocational and technical training workshops executed by General Directorate of Vocational and Technical Education in 2012) are presented. 